\title{
Fibromiyaljide güncel ilaç tedavisi
}

\author{
Current drug treatment in fibromyalgia \\ Seval Pehlevan \\ Özel Medical Park Gebze Hastanesi, İç Hastalıkları Romatoloji Kliniği, Kocaeli
}

\section{Öz}

Fibromiyalji (FM); kronik ağrı, yorgunluk ve fonksiyon bozukluğu ile karakterize bir hastalıktır. Genetik yatkınlık beraber çevresel ve psikolojik faktörlerde hastalığın oluşumda etkili olabilir. Serotonin ve katekolaminlerin ileti bozukluğu FM'de ağrı mekanizmasında rol oynar. İlaç tedavisi ağrıyı azaltmaya ve diğer semptomların iyileşmesine odaklanır. Hastalığın tedavisinde eğitim, bilişsel davranışçı terapi, egzersiz gibi ilaç dışı tedaviler ve farmakolojik tedavilerin yer aldığı çok yönlü yaklaşım gereklidir. FM'de tedavi, hastanın semptomlarının sayısına ve çeşitliliğine göre, tek bir uzman veya bir takım (romatoloji uzmanı, nöroloji uzmanı, psikiyatri uzmanı) tarafından yapılır. Farmakolojik tedavide en sık antidepresanlar (amitriptilin, siklobenzaprin, duloksetin, milnasipran) ve antikonvülsanlar (pregabalin, gabapentin) kullanılır. Uluslararası FM tedavi önerileri temel olarak aerobik egzersiz, bilişsel-davranışçı terapi ve amitriptilin gibi ilaç tedavisi yapılmasına odaklanmaktadır.

Anahtar Sözcükler: Fibromiyalji, güncel, ilaç tedavisi.

\begin{abstract}
Fibromyalgia (FM), a disorder characterized by widespread chronic musculoskeletal pain, fatigue and dysfunction. Together with the genetic predisposition, it may be effective in the emergence of the disease in environmental and psychological factors. The aim of drug therapy in fibromyalgia is to reduce pain and improve other symptoms. Nonpharmacological therapies like cognitive behavioral therapies, training, exercise and pharmacologic therapies need versatile approach. Fibromyalgia treatment is performed by a single specialist or a team (rheumatologist, neurologist, and psychiatrist) according to the number and variety of the patient's symptoms. In pharmacological treatment, antidepressants (amitriptyline, cyclobenzaprine, duloxetine, milnacipran) and anticonvulsants (pregabalin, gabapentin) are most commonly used. International fibromyalgia treatment recommendations focus mainly on aerobic exercise, cognitive-behavioral therapy and drug therapy such as amitriptyline.
\end{abstract}

Keywords: Fibromyalgia, current, drug treatment.

\section{Giriş}

Fibromiyalji (FM) yaygın vücut ağrısı, yorgunluk, uyku bozukluğu, anksiyete ve kavrama bozukluğu ile karakterize olan kronik bir hastalıktır (1). Hastalar sıklıkla kötü yaşam kalitesinden şikâyet ederler. FM tüm dünyada osteoartritten sonra en sık görülen ikinci romatolojik hastalıktır (2). FM'nin Amerika Birleşik Devletleri'nde yetişkin nüfusun \%6'sını ve tüm dünya yetişkinlerin \%3'ünü etkilediği tahmin edilmektedir. Kadınlara erkeklerden 3-6 kat daha yüksek oranda FM tanısı konur (3). FM'li bireylerin diğer aile üyelerinde kronik ağrı durumları veya FM görülme olasıı̆ğı yüksektir. Genetik yatkınlık sıktır. Çevresel faktörler ve psikolojik durumlar FM'yi tetikleyebilir (2).

Yazışma Adresi: Seval Pehlevan

Özel Medical Park Gebze Hastanesi, İç Hastalıkları Romatoloji Kliniği, Kocaeli

E-mail: sevalpehlevan@gmail.com
FM'de 'merkezileştirilmiş' ağrı durumu vardır. Bu tanım, ağrının merkezi sinir sisteminde kaynaklandığını veya ağrının abartılı olarak ifade edildiğini gösterebilir. Serotonin ve katekolaminler (norepinefrin, epinefrin ve dopamin) merkezi sinir sistemindeki ana nörotransmitter ve katekolaminler sempatik nörotransmitterdir. Serotonin ve norepinefrin beyin ve omurilikte inen inhibitör ağrı yolaklarında yer alır. $\mathrm{Bu}$ nörotransmitterlerin ileti bozukluğu FM'deki ağrı mekanizmasında ve ağrının merkezi sensitizasyonunda önemli rol oynar (4). Serotonin insan vücudu tarafından üretilen ve ağrı, uyku ve ruh hali üzerine etkisi olan kimyasaldır (5).

Tedavide genel amaç; hastanın hayat kalitesinin artırılması ve günlük durumlarda fonksiyonel yeteneğin korunmasıdır (5). Bu hastalarının tedavisinde; eğitim, bilişsel davranışçı terapi, egzersiz gibi ilaç dışı tedaviler ve farmakolojik tedaviden oluşan çok yönlü bir yaklaşım gerektirdiği konusunda genel bir fikir birliği vardır. Fibromiyalji tedavisi, hastanın semptomlarının sayısına ve çeşitliliğine göre tek bir uzman veya birkaç uzman 
(romatoloji uzmanı, nöroloji uzmanı, psikiyatri uzmanı) tarafından yapılır (6).

Tanı; anamnez, fizik muayene bulguları (kas, eklem ve tendon muayenesi ile genel hassasiyet gösterilir), ağrı ve yorgunlukla ilişkili patolojik başka durumların dışlanması ve normal laboratuvar değerleri ile konulur. Hastalığın yapısı, tedavi yöntemleri ve hastalık seyri açısından hastaya eğitim verilmeli ve ilaç dışı tedaviler anlatılmalıdır. FM'nin patogenezini değiştiren özel bir tedavi olmadığından, ilaç tedavisi ağrıyı azaltmaya ve diğer semptomların iyileşmesine odaklanır (7). FM'de kullanılan ilaçlar Tablo-1'de görülmektedir.

Tablo-1. Fibromiyalji tedavisinde kullanılan farmakolojik ajanlar.

\begin{tabular}{l}
\hline Antidepresanlar \\
\hline Trisiklik antidepresanlar \\
\hline Selektif serotonin gerialım inhibitörleri (SSGi) \\
\hline Serotonin-noradrenalin geri alım inhibitörleri (SNGi) \\
\hline Antikonvülsan ilaçlar \\
\hline Pregabalin \\
\hline Gabapentin \\
\hline Sedatif hipnotikler \\
\hline Nonsteroid antiinflamatuvar ilaçlar \\
\hline Opioidler
\end{tabular}

\section{Antidepresan İlaçlar}

Antidepresan ilaçlar, serotonin ve noradrenalin geri alımını inhibe ederek, noradrenalin ve serotonin düzeyini artırır (7).

Trisiklik antidepresan ilaçlar (amitriptilin, siklobenzaprin): Antidepresan olarak ilk kullanılan ilaç grubu olan trisiklik antidepresanlar (TSA) merkezi sinir sisteminde (MSS) serotonin ve noradrenalin geri emilimini bloke ederler. TSA ile ilgili yapılmış üç meta analiz çalışmasında FM'de ağrı ve uyku kalitesi üzerine yararlı olduğu gösterilmiştir. FM'de en sık reçete edilen ilaçlardan biri olmasına rağmen Amerikan Gıda ve İlaç Dairesi (FDA) tarafından onaylı değildir. 25-50 mg dozlarda gece tek doz olarak verilir, bu dozlar depresyon için gereken dozlardan daha düşüktür. FM de uyku kalitesi ve ağrı üzerine daha değişken ve ılımlı etkisi vardır. Polinöropatik ağrı da uzun süreli kullanımı vardır. Antikolinerjik, antiadrenerjik ve antihistaminik etkilerinden kaynaklanan tolerans problemleri vardır. Yan etkileri ağız kuruluğu, konstipasyon, sıvı retansiyonu, kilo alma, konsantrasyon güçlüğü, halsizlik ve sersemliktir. Yaşılıarda kardiyovasküler olaylardan dolayı dikkatli kullanılmalıdır.

Siklobenzaprin, yapı olarak bir TSA olmasına rağmen bir kas gevşetici olarak sınıflandırıır. Hafif ve orta şiddette bulguları olan FM hastaların da kullanılır. Minimal antidepresan etkisi de var. Önerilen dozu yatarken 10 mg'dır. Randomize sekiz haftalık bir çalışmada düşük doz siklobenzaprin'in (1-4 mg/yatarken) FM'li hastalarda ağrı, yorgunluk ve depresyonda belirgin bir düzelme yaptığı gösterilmiştir (8).
Selektif serotonin geri alım inhibitörleri (SSGI): TSA'lara göre daha iyi tolere edilebilen ajanlardır. Klinik pratikte en sık kullanılanlar sitalopram, fluoksetin, essitalopram, fluvoksamin, paroksetin ve sertralindir. Bu ilaçların FM'nin temel semptomları olan, ağrı, yorgunluk ve uyku problemlerini tedavi etmede plasebodan daha üstün olduklarını gösteren hiçbir kanıt yoktur. Bu yüzden FM tedavisinde onay almamışlardır. FM'li hastalarda depresyon tedavisinde düşünebilirler. Majör depresif bozukluğundan dolayı bu ilaçları alması gereken 18-24 yaş arası genç erişkinlerde, artmış intihar eğilimi için kara kutu uyarısı uygun olduğunda düşünülmelidir (9).

Serotonin noradrenalin geri alım inhibitörleri (SNGI): Duloksetin, milnasipran ve venlafaksin santral sinir sisteminde serotonin ve noradrenalin geri alımının selektif güçlü inhibitörleridir. Duloksetin ayrıca diyabetik periferik nöropati, osteoartrite bağlı kronik ağrılarda, majör depresyon, genel anksiyete bozuklukları, idrar inkontinansı ve kronik bel ağrısında da kullanılır. Duloksetin, FDA dan depresyon, diyabetik periferik nöropati ve FM ağrısı için onayı bulunan bir ilaçtır. Toplam onsekiz çalışma ve 6407 katılımcıyı içeren bir metanalizin altı çalışmasında 2249 FM'li hasta değerlendirilmeye alınmıştır. Duloksetin $60 \mathrm{mg} 12$ hafta boyunca ağrıyı azaltmada etkili olduğu (RR for $\geq \% 50$ ağrı azalması $1.57, \% 95 \mathrm{Cl} 1.20-2.06$ ) ve 28 hafta boyunca (RR 1.58, \%95 Cl 1.10 - 2.27) etkinin devam ettiğini gösterilmiştir. Bu çalışmada duloksetinin 20-30

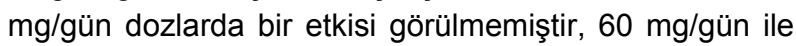
etkinlik görülmüş ve ayrıca $60 \mathrm{mg}$ ile $120 \mathrm{mg}$ arasında etki açısından fark saptanmamıştır. Depresyonun ağıılı fiziksel bulguların da düzelme görülmüş. Yan etki sıktır ama çoğunlukla hafiftir, doza bağlıdır. En sık görülen yan etkiler; yorgunluk, hasta hissetme, çok uyanık olma veya uykusuzluk, baş ağrısı, ağız kuruluğu, kabızlık veya baş dönmesidir. Duloksetinin neden olduğu ciddi problemler çok nadirdir (10).

Milnasipran, duloksetinden biraz daha fazla noradrenerjik etki gösterebilir, bu yüzden yorgunluk ve hafıza problemlerinde daha faydalıdır. Noradrenerjik etkisi daha fazla olduğu için hipertansiyon da daha sık görülür. Ağrı ve yorgunlukta azalma, zihinsel ve fiziksel fonksiyonlarda artış sağladığı gösterilmiştir. Sabah 12.5 $\mathrm{mg} / \mathrm{gün}$ dozu ile başlanır, yavaşça doz artırır, tolere edilirse 50 mgx2/gün'e kadar çıkılabilir. Randomize çalışmalarda ağrı ve global durumda plasebodan daha fazla düzelme gösterilmiş. Yan etki bulantı, baş ağrısı ve konstipasyondur. Yan etkiler nedeniyle ilacı bırakma oranı \%23-26'dır (11).

Milnasipran ile yapılan çift kör, plasebo kontrollü çalışmaya 1025 hasta alınmıştır. Hastalara 12 hafta boyunca 50 mgx2 Milnasipran verilmiştir. Çalışma sonunda ağrı, global durumda, fiziksel ve mental durumda düzelme saptanmıştır. Ayrıca yorgunluk ve depresyonda belirgin düzelme görülmüştür. En sık yan 
etki bulantıdır. Kan basıncı ve kalp hızı kontrol edilmesi önerilmiştir (12).

Venlafaksin, diğer bir selektif serotonin ve noradrenalin inhibitörüdür. Sınırlı data vardır. Yarılanma ömrü kısadır, doz atlanırsa yoksunluk belirtileri daha kolay görülebilir.

\section{Antikonvülsan İlaçlar}

Epilepsi tedavisi için geliştirilen bu ilaçların ağrı giderici etkileri olabileceği uzun süredir bilinmektedir. Bu ilaçlar içinde en iyi biline pregabalin ve gabapentindir.

Pregabalin, yapısal olarak nörotransmitter $\gamma$-aminobütirik asit (GABA) analoğudur. Alfa-2-delta ( $\alpha 2 \delta$ ) yardımcı proteinleri ile ilişkili olan voltaj geçişli kalsiyum kanallarına bağlanır ve sinire kalsiyum akışını düzenler. Glutamat ve $\mathrm{P}$ maddesi gibi ağrıda rol oynayan nörotransmitterlerin salınımını azaltır. FDA tarafından fibromiyalji tedavisinde ilk onay almış ilaçtır. Ayrıca diyabetik periferik polinöropati, postherpetik nevralji ve parsiyel başlangıçlı nöbetlerde de kullanımı vardır (13). Pregabalinin FM'de etkili olduğunun gösterildiği ilk çalışmada, 529 hastaya 150/300/450 mg pregabalin ve plasebo verilmiştir. Ağrıda \%50'den daha fazla düzelme; $450 \mathrm{mg}$ pregabalin alan hastalarda $(\% 28,9)$ plasebodan $(\% 13,2)$ daha yüksek $(p=0.003)$ bulunmuştur (14). Pregabalinin yüksek dozlarda kullanıldığı başka bir çalışmada ise; 745 hastaya yüksek doz pregabalin $(300$, 450 ve $600 \mathrm{mg}$ ) ve plasebo verilmiş. Ağrıda \%50'den fazla düzelme tüm tedavi gruplarında plasebodan daha yüksek ( $p=0.03, p=0.04$ ve $p=0.01$ ) bulunmuştur (15). Pause ve ark.'larının yaptığı uluslararası, randomize, çift kör çalışma, toplam 73 merkezden (Avrupa, Kanada, Avustralya ve Asya) 747 hasta çalışmaya alınmış, pregabalin $300,450,600 \mathrm{mg}$ ve plasebo verilmiştir. Ağrıda $\% 30$ ve $\% 50$ 'den fazla azalma, 300 ve $450 \mathrm{mg}$ dozlarda belirgin farklı iken $600 \mathrm{mg}$ dozunda belirgin fark bulunmamış (16). FM'de pregabalinin etkinliğini ve etkinin devamlılığını araştıran FREEDOM çalışmasında pregabalinin ağrı da belirgin düzelme yaptığı ve uyku, yorgunluk ve fonksiyonel durumda da iyileşme yaptığı, güvenli, uyumu kolay ve uzun süreli kullanıma uygun bir ilaç olduğu söylendi. Bu çalışmanın sonunda pregabalin alanların \%50'sinde halen etkinin devam ettiği gösterildi (17).

Pregabalin en sık yan etkileri baş dönmesi (\%40-50) ve uyuklamadır (\%30-40). Baş dönmesi doz ile ilişkilidir uyuklama doz ile ilişkisizdir, ortalama süresi, 18-88 gündür. Kilo alımı ve periferik ödem daha az sıklıkla görülür ama tedavinin kesmesine daha sık neden olur. Kilo alımı tedavinin üçüncü ayından sonra görülür, uzun süreli çalışmalarda pregabalin alan hastalarda kilo alım oranı \%18-26'dır. Periferik ödem tedavinin üçüncü ayında \%8-11 oranında görülür, ilaç bırakma oranı \%0,5 den daha azdır. Periferik ödemli hastalarda kalp ve böbrek fonksiyonları normaldir ama klas 3-4 kalp yetmezliği olan hastalarda dikkatli kullanmalıdır.
Antikonvülsan olarak adlandırılan gabapentinin etki mekanizması tam olarak bilinmemekle beraber doza bağımlı olarak beynin tüm glial yapılarında GABA sentez ve salınımını arttırır. Voltaj bağımlı kalsiyum kanallarında bulunan alfa-2-delta subligandına yüksek afinite göstererek monoamin yapıdaki nörotransmitterlerde azalmaya sebep olur. Kullanım dozu 900-3600 mg/gün'dür. FM'de gabapentin kullanımı ağrıda azalma, yaşam kalitesinde artma ve uykunun hem miktar hem de kalitesinde artış sağladığı gösterilmiştir (18). Gabapentinin, FM tedavisinde etkinliğini araştıran tek bir randomize kontrollü çalışması vardır (150 hasta ve kontrol). Ağrı, uyku, fonksiyon ve hasta global değerlendirmesi de belirgin düzelme olduğu gösterilmiştir (19).

\section{Sedatif Hipnotikler}

Sodyum hidroksibütirat, santral sinir sistemi üzerine depresan etki gösteren GABA'nın endojen bir metaboliti olan gama hidroksibütiratın sodyum tuzuyla birleşiminden oluşan bir ilaçtır. İlacın oral formu SBX (Xyrem) narkolepsi hastalarındaki katapleksi ve çeşitli semptomların tedavisinde Amerika, Avrupa ve Kanada'da onay almıştır.

Sedatif hipnotikler FM'de yavaş dalga süresini uzatır, gece boyunca uyanmaları azaltır. Böylece bozulmuş uykuyu veya dinlendirmeyen uykuyu düzeltmek amacıyla kullanılırlar. Uyku düzeltilerek diğer fonksiyonlar olan yorgunluk ve idrak bozukluğu gibi şikâyetleri azaltabilir. En sık yan etkiler bulantı, baş ağrısı, uyuşukluk ve baş dönmesi, genelde iyi tolere edilir. Eğlendirici olarak kötüye kullanılabileceği için FDA'dan onay almamıştır.

\section{Nonsteroid Antiinflamatuvar İlaçlar}

FM'de etkili olduklarına dair kanıt yoktur. Ama beraberinde olan romatizmal hastalıkların tedavisinde yararlı olabilir. Yan etkiyi azaltmak için en düşük dozda en kısa sürede verilebilir (20). NSAil'lar tek başlarına kullanıldığında etkisi olmamakla beraber bir TSA ile beraber kullanıldığında etkilidir (21).

\section{Tramadol}

Santral etkili, sentetik opioid reseptör agonistidir. Serotonin noradrenalin reseptör inhibitör etkinliği de vardır. Mu-opioid reseptörlerine karşı zayıf agonist gibi davranır (22). Bennett ve ark.larının yaptığı randomize, çift kör, kontrollü çalışmada 315 hastada, $37.5 \mathrm{mg}$ tramadol / $325 \mathrm{mg}$ asetaminofen tablet verilmiştir. Primer sonuç ölçümü; ilaç kesilme zamanı olarak alınmıştır. Sonuçta; Tramadol/asetaminofen kullanan hastalarda plasebo ile karşılaştırılığında daha az ilaç bırakılması vardır (\%48-\%62, p=0.004). Görsel ağrı skalası (VAS) ilaç alan grupta plasebodan daha düşüktür $(p<0.001)$. Yan etki olarak bulantı, baş dönmesi, somnolans ve konstipasyon görülmüştür (23).

Almanya'da tüketici raporlarına göre en zararlı tedavi olarak ilk sırada yer alırlar. Kanada ve Alman kılavuzları 
bağımlılık yan etkisi ve kötüye kullanım nedeniyle güçlü opioidleri kesinlikle önermezken, Amerika kılavuzları FM'li hastalarda opioid kullanımının uygun olmadığını vurgulamışlardır. FM tedavisinde kanıtların yetersizliğine, tedavi kılavuzlarının destek azlığına rağmen opioid kullanımı devam etmektedir (24).

\section{Monoamin Oksidaz İnhibitörleri}

Monoamin oksidaz-A (MAO-A) enzimi serotonin ve noradrenalini parçalar. Moklobemid ve pirlindol selektif MAO-A inhibitörü olan ilaçlardır. Antidepresan etkilerinden bağımsız olarak analjezik etkileri de vardır. Bu ilaçlar ile yapılan bir meta analiz de toplam 230 hasta değerlendirilmiştir. Pirlindolün ağrı, hassas nokta ve hasta-doktor global değerlendirme de etkisi varken aynı etkinlik moklobemid ile görülmemiştir. En sık yan etkileri bulantı ve kusmadır. FM'de MAO-A inhibitörlerinin etkisini gösteren data azlığı nedeni ile çok tercih edilmezler (25)

FM tedavisinde Amerikan İlaç ve Gıda İdaresi (FDA)'nden onay almış ilaçlar pregabalin, duloksetin ve milnasiprandır. Lee ve ark.ları bu ilaçların FDA da önerilen dozları (duloksetin $60 \mathrm{mg}$, pregabalin $300 \mathrm{mg}$, pregabalin $150 \mathrm{mg}$, milnasipran $100 \mathrm{mg}$, milnasipran 200 $\mathrm{mg}$ ) ve plasebo etkinliğini ve tolere edilebilirliğini araştıran bir meta analiz yapmışlardır. Bu analizde dokuz randomize kontrollü çalışmada 5140 hastanın 814 haftalık izlem sonuçları değerlendirilmiştir. Sonuç ölçekleri olarak; ağrısı \%30'dan fazla düzelen hasta sayısı ve yan etkiden dolayı ilacı bırakan hasta sayısı alınmıştır. Önerilen dozlarda bu ilaçlar arasında etkinlik ve güvenlik açısından belirgin bir fark bulunmamıştır (26).

Amerika Birleşik Devletleri'nde sağlık hizmeti kullanım verilerini kullanarak, geniş popülasyon tabanlı bir kohort çalışmasında, amitriptilin, duloksetin, gabapentin ve pregabalin'in yeni başlandığı FM hastalarının klinik özellikleri ve ilaç kullanım düzenlerini tanımlanmıştır. FM ile ilişkili en sık görülen klinik bulgu sırt ağrısı, sonra baş ağrısı ve uyku bozukluğudur. Yaşlılarda, kadınlarda, sigara içenlerde ve daha yüksek komorbidite indeksi olanlarda, sırt ağrısı ve diyabet tanısı olanlarda diğer üç ilaçla karşılaştırıldığında gabapentin ile tedaviye başlatılma olasılığı daha yüksektir. Başlangıçta baş ağrısı, karın ağrısı ve uyku bozukluğu olan hastalarda, amitriptilinin ilk ilaç olarak verilme oranı daha yüksektir. Depresyon ve anksiyetesi olanlarda duloksetin ile tedaviye başlatılması daha çok tercih edilmiş. Abdominal ağrı, uyku bozukluğu ve inflamatuar artrit tanısı pregabalin ile tedavi edilme olasılığını artırır (27).

FM'de farklı mekanizmaların sorumlu olduğu birçok semptom olduğu için, tedavide de farklı etki mekanizması olan ilaçlar kullanılabilir. Gilron ve ark.'larının yaptığı FM tedavisinde pregabalin ve duloksetin'in kombinasyonunun değerlendirildiği, tek merkezli, randomize, çift kör, kontrollü çalışmada, ağrıyı azaltmada kombinasyon tedavisinin plasebodan ve pregabalinden daha üstün olduğu ama duloksetinden üstün olmadığı bulunmuştur (28).

Avrupa Romatoloji Birliği (EULAR) önerilerinde (12 ülkeden toplam 18 üye ile) FM tanısı doğrulandıktan sonra, hastaya öncelikle hastalığı hakkında bilgi ve eğitim verilmesi ve fiziksel egzersiz yapması gerektiği anlatılır. Eğer hastada şiddetli ağrı, bilişsel semptomlar veya uyku bozuklukları varsa, farmakolojik veya psikolojik bir yaklaşım tercih edilmesi önerilir. Toplam 9 öneri vardı ve sadece üç öneri literatüre dayanıyordu, çoğu öneri uzman görüşüne bağlıydı. Bireyselleştirilmiş ilaç tedavileri en çok önerildi. Sonuçta amitriptilin (düşük dozlarda), duloksetin veya milnasipran, tramadol, pregabalin ve siklobenzaprin zayıf güçlü olarak önermişlerdir. FM tedavisinde kortikosteroidler, güçlü opioidler, kannabinoidler ve antipsikotikler kullanımına, etkili olduklarına dair kanıt olmaması ve yan etkinin fazla olması ve bağımlılık riskinden dolayı kullanılmaması bildirilmiştir (29).

Diğer uluslararası öneriler (Amerika 2015, Almanya 2012 ve Kanada 2013) temel olarak aerobik egzersiz, bilişseldavranışçı tedavi ve amitriptilin gibi ilaç tedavisi yapılmasına odaklanmaktadır. FM'de hastalarının geniş semptomatik spektrumu ve araştırma çalışmalarının metodolojik heterojenliği nedeniyle uluslararası kılavuzlar arasında hala bir fikir birliği yoktur (30).

\section{Sonuç}

Fibromiyalji sendromunun tedavisi multidisipliner bir yaklaşım gerektirmektedir. Tedavide kullanılan farmakolojik ajanlar çok çeşitlidir ancak sınırlı sayıda kanıt düzeyi yüksek ilaç bulunmaktadır. FDA dan onay almış sadece üç ilaç vardır: Pregabalin, duloksetin, milnasipran. Multidisipliner yaklaşımla farmakolojik ajanları, nonfarmakolojik yöntemler ile kombine kullanmak en doğru yaklaşım olacaktır.

\section{Kaynaklar}

1. Kia S, Choy E. Uptodate on treatment guideline in fibromyalgia syndrome with focus on pharmacology. Biomedicines $2017,5(2)$. pii: E20. doi: 10.3390/biomedicines5020020.

2. Clauw D. Fibromyalgia a clinical review. JAMA 2014;311(15):1547-55.

3. Liu Y, Qian C,Yang M, Treatment Patterns Associated with ACR-Recommended Medications in the Management of Fibromyalgia in the United States. J Manag Care Spec Pharm 2016;22(3):263-71.

4. Theoharides TC, Tsilioni I, Arbetman L, et al. Fibromyalgia syndrome in need of effective treatments. J Pharmacol Exp Ther 2015;355(2):255-63 
5. Hauser W, Abline J, Perrot S, Fitzcharless MA. Management of fibromyalgia: key messaes from evidence-based guidelines. Pol Arch Intern Med 2017;127(1):47-56.

6. Borchers AT, Gershwin ME. Fibromyalgia: a critical and comprehensive review. Clinic Rev Allerg Immunol 2015;49(2):100-51.

7. Walitt B, Urruita G, Nishishinya MB, Cantrell SE, Hauser W. Selective serotonin reuptake inhibitors for fibromyalgia syndrome. Cochrane Database of Systematic Reviews, 2015 Jun 5;(6): CD011735. doi: 10.1002/14651858.CD011735.

8. Moldofsky H, Harris HW, Archambault WT, Kwong T, Lederman S. Effects of bedtime very low dose cyclobenzaprine on symptoms and sleep physiology in patients with fibromyalgia syndrome: a double-blind randomized placebo-controlled study. $J$ Rheumatol. 2011;38(12):2653-63.

9. Walitt B, Urrútia G, Nishishinya MB, Cantrell SE, Häuser W. Selective serotonin reuptake inhibitors for fibromyalgia syndrome. Cochrane Database Syst Rev 2015 Jun 5;(6):CD011735.

10. Lunn MPT. Lunn MP, Hughes RA, Wiffen PJ. Duloxetine for treating painful neuropathy, chronic pain or fibromyalgia. Cochrane Database Syst Rev 2014 Jan 3;(1)

11. Cording M, Derry S, Phillips T, Moore RA, Wiffen PJ. Milnacipran for pain in fibromyalgia in adults. Cochrane Database Syst Rev 2015 Oct 20;(10):CD008244.

12. Arnold LM, Gendreau MR, Palmer RH, Gendreau JF, Wang Y. Efficacy and safety of milnacipran $100 \mathrm{mg} /$ day in patients with fibromyalgia results of a randomized, double-blind, placebo-controlled trial. Arthritis Rheum 2010;62(9):2745-56.

13. Mease PJ, Dundon K, Sarzi-Puttini P. Pharmacotherapy of fibromyalgia. Best Pract Res Clin Rheumatol 2011;25(2):285-97.

14. Crofford LJ, Rowbotham MC, Mease PJ, et al. Pregabalin for the treatment of fibromyalgia syndrome: results of a randomized, double-blind, placebo-controlled trial. Arthritis Rheum 2005;52(4):1264-73.

15. Arnold LM, Russell IJ, Diri EW, et al. A 14-week, randomized, double-blinded, placebo-controlled monotherapy trial of pregabalin in patients with fibromyalgia. J Pain 2008;9(9):792-805.

16. Pauer L, Winkelmann A, Arsenault $P$, et al. An international, randomized, double-blind, placebo-controlled, phase III trial of pregabalin monotherapy in treatment of patients with fibromyalgia. J Rheumatol 2011;38(12):2643-52.

17. Crofford LJ, Mease PJ, Susan L, et al. Fibromyalgia relapse evaluation and efficacy for durability of meaningful relief (FREEDOM): A 6-month, double-blind, placebo-controlled trial with pregabalin. Pain 2008;136(3):419-31.

18. Rose MA, Kam PC. Gabapentin: pharmacology and its use in pain management. Anaesthesia 2002;57(5):451-62.

19. Arnold LM, Goldenberg DL, Stanford SB, et al. Gabapentin in the treatment of fibromyalgia: a randomized, double-blind, placebo-controlled, multicenter trial. Arthritis Rheum 2007;56(4):1336-44.

20. Clauw DJ. Fibromyalgia: a clinical review. JAMA 2014;311(15):1547-55.

21. Goldenberg DL, Felson DT, Dinerman H. A randomized, controlled trial of amitriptyline and naproxen in the treatment of patients with fibromyalgia. Arthritis Rheum 1986;29(11):1371-7.

22. MacLean AJ, Schwartz TL. Tramadol for the treatment of fibromyalgia. Expert Rev Neurother 2015;15(5):469-75.

23. Bennett RM, Kamin M, Karim R, Rosenthal N. Tramadol and acetaminophen combination tablets in the treatment of fibromyalgia pain: a double-blind, randomized, placebo-controlled study. Am J Med 2003 May;114(7):537-45.

24. Aşkın A, Özkan A. Pharmacological treatment in fibromyalgia. Archives Medical Review Journal 2017;26(1):124-41.

25. Tort S, Urrútia G, Nishishinya MB, Walitt B. Monoamine oxidase inhibitors (MAOIs) for fibromyalgia syndrome. Cochrane Database Syst Rev 2012 Apr18;(4):CD009807.

26. Lee YH, Song GG. Comparative efficacy and tolerability of duloxetine, pregabalin, and milnacipran for the treatment of fibromyalgia: a Bayesian network meta-analysis of randomized controlled trials Rheumatol Int 2016;36(5):663-72.

27. Kim SC, Landon JE, Solomon DH. Clinical characteristics and medication uses among fibromyalgia patients newly prescribed amitriptyline, duloxetine, gabapentin, or pregabalin. Arthritis Care Res (Hoboken) 2013;65(11):1813-9.

28. Gilron I, Chaparro LE, Tu D, et al. Combination of pregabalin with duloxetine for fibromyalgia: a randomized controlled trial. Pain 2016;157(7):1532-40.

29. Macfarlane GJ, Kronisch C, Dean LE, et al. EULAR revised recommendations for the management of fibromyalgia. Ann Rheum Dis 2017;76(2):318-28

30. Talotta R, Bazzichi L, Di Franco M, et al. One year in review 2017: fibromyalgia. Clin Exp Rheumatol 2017;35 (Suppl.105):6-12. 